\title{
PRODUÇÃO E QUALIDADE DO LEITE DE CABRAS DE TORNEIOS LEITEIROS
}

\author{
A.H.N. Rangel ${ }^{1}$, T.I.C. Pereira ${ }^{2}$, M.C. Albuquerque Neto ${ }^{1}$, H.R. Medeiros ${ }^{1}$, \\ V.M. Araújo ${ }^{2}$, L.P. Novais' ${ }^{2}$ M.R. Abrantes ${ }^{3}$, D.M. Lima Júnior ${ }^{4}$ \\ ${ }^{1}$ Universidade Federal do Rio Grande do Norte, Escola Agrícola de Jundiaí, Unidade Acadêmica Especia- \\ lizada em Ciências Agrárias, CP7, CEP59280-000, Macaíba, RN, Brasil.E-mail:adrianohrangel@yahoo.com.br
}

\section{RESUMO}

\begin{abstract}
O objetivo deste trabalho foi avaliar a produção diária, a qualidade microbiológica e físicoquímicas do leite das cabras participantes de Torneios Leiteiros no Estado do Rio Grande do Norte, Brasil. Foram analisadas 111 amostras de leite de 106 cabras (39 Saanen, 6 Toggenburg e 61 mestiças) agrupadas em categorias pela ordem de parto (primíparas e pluríparas) e estágio de lactação [inicial (0 a 30 dias), pico (30 a 45 dias) e pós-pico (mais de 45 dias)], utilizando o delineamento inteiramente casualisado. As cabras pluríparas apresentaram maiores médias de produção no início $(4,41 \mathrm{~kg} /$ dia $)$ e no pico $(5,42 \mathrm{~kg} /$ dia $)$ de lactação. Entre raças não houve diferença para produção media $(4,62 \mathrm{~kg} / \mathrm{dia})$, ponto de congelamento $\left(-0,488^{\circ} \mathrm{C}\right), \mathrm{pH}(6,64)$, densidade $(1,030 \mathrm{~g} / \mathrm{L})$, gordura $(3,60 \%)$, proteína $(2,90 \%)$, lactose $(4,89 \%)$, extrato seco desengordurado $(8,41 \%)$ e extrato seco total $(12,06 \%)$. As análises microbiológicas revelaram a presença de mesófilos e coliformes fecais, sem diferença entre as ordens de parto ou entre raças. Cabras pluríparas apresentaram maiores produções de leite, mas não diferiram das primíparas quanto à composição, características físicas e microbiota do leite. As amostras de leite dos três genótipos (Saanen, Toggenburg e mestiças) analisados mostraram características físico-químicas, microbiológicas e de produção semelhantes.
\end{abstract}

PALAVRAS-CHAVE: Caprinos, ordem de parto, raças, semiárido.

\section{ABSTRACT}

MILK PRODUCTIONAND QUALITY IN DAIRY GOATS THAT PARTICIPATE IN DAIRY TOURNAMENTS IN THE STATE OF RIO GRANDE DO NORTE, BRAZIL. The objective of this study was to evaluate the average daily production, the physicochemical components and microbiological agents in milk of primiparous and multiparous dairy goats that participate in dairy tournaments in the state of Rio Grande do Norte, Brazil. Analyses were carried out on 111 samples of goat milk from 106 goats (39 Saanen, 6 Toggenburg and 61 crossbred) grouped into categories by number of parity (primiparous and multiparous) and stage of lactation [initial (0 to 30 days), peak (30 to 45 days) and decrease (over 45 days)]. The data were analyzed in a completely randomized design. The multiparous goats had higher average production at the beginning ( $4.41 \mathrm{~kg} /$ day) and peak $(5.42 \mathrm{~kg} /$ day) of lactation. Between breeds there was no difference for average production $\left(4.62 \mathrm{~kg} /\right.$ day), freezing point $\left(-0.488^{\circ} \mathrm{C}\right), \mathrm{pH}(6.64)$, density $(1.030 \mathrm{~g} / \mathrm{L})$, fat $(3.60 \%)$, protein $(2.90 \%)$ lactose $(4.89 \%)$, dry extract $(8.41 \%)$ or total solids $(12.06 \%)$. Mesophiles $(\log \mathrm{CFU} / \mathrm{mL})$ and fecal coliforms $(\log \mathrm{MPN} / \mathrm{mL})$ were found in milk from goats, but no difference was observed between the orders of parity or between breeds. Multiparous goats had higher milk production, but did not differ from the primiparous goats regarding the composition, physical characteristics and microbiology of milk. The milk of 3 breeds (Saanen, Toggenburg and crossbred) presented similar physico-chemical, microbiological and production characteristics.

KEY WORDS: Goats, parity, breeds, semiarid.

\section{INTRODUÇÃO}

A região Nordeste do Brasil detém o maior contingente de caprinos $(91,0 \%)$ e produz cerca de $67,0 \%$ do leite de cabra no país (IBGE, 2006). A despeito desses montantes, as criações desses pequenos ruminantes são conduzidas, na maioria das vezes, de forma inadequada, com pouca adoção de

${ }^{2}$ Universidade Federal do Rio Grande do Norte, Unidade Acadêmica Especializada em Ciências Agrárias, Macaíba, RN, Brasil.

${ }^{3}$ Universidade Federal Rural do Semiárido, Mossoró, RN, Brasil.

${ }^{4}$ Universidade Federal Rural de Pernambuco, UFRPE, Recife, PE, Brasil. 
tecnologias. Estas poderiam contribuir fortemente para aumentar a produção e melhorar a qualidade do produto.

No que concernem às potencialidades, o leite caprino apresenta características organolépticas e físico-químicas singulares. Gordura e proteína de elevada digestibilidade tornam o leite caprino atraente aos consumidores com disfunções digestivas e baixos teores de lactose também tornam o leite caprino menos alergênico às pessoas intolerantes (RIBEIRO; RIBEIRO, 2001).

Informações sobre composição e características físico-químicas do leite caprino são essenciais para o sucesso da indústria láctea, bem como para o marketing de seus derivados (PARK et al., 2007). A Instrução Normativa $n^{\circ} 37$ estabelece que o leite de cabra deve apresentar teor de gordura de acordo com sua classificação, acidez de $0,13 \%$ a $0,18 \%$, extrato seco desengordurado mínimo de $8,2 \%$, densidade a $15^{\circ} \mathrm{C}$ de $1,028 \mathrm{~g} / \mathrm{mL}$ a $1,034 \mathrm{~g} / \mathrm{mL}$, crioscopia de $-0,530^{\circ} \mathrm{C}$ a $-0,564^{\circ} \mathrm{C}$, proteína total, mínimo, de 2,8\%, lactose, mínima, $4,3 \%$ e cinzas 0,7\% (BRASIL, 2000).

Dentre os fatores que influenciam a produção e composição do leite de cabra ressaltam-se a raça, a idade da matriz, ordem de parto, estágio da lactação, variabilidade genética individual e, principalmente, o manejo alimentar e da nutrição, particularmente quanto à quantidade e qualidade da dieta (SAnz SAMPELAYO et al., 2007). ZAMBOM et al. (2005), ao trabalhar com diferentes relações de volumoso:concentrado para cabras Saanen, pluríparas, encontraram antecipação do pico de lactação de 71 dias para 21 dias pós-parto. Ainda, registraram produções menores no pico, de $3,42 \mathrm{~kg}$ para $1,86 \mathrm{~kg}$, para cabras alimentadas com $80,0 \%$ de volumoso e $20,0 \%$ de concentrado, com dietas baseadas em silagem de milho.

PAz et al. (2007), na Argentina, estudando a influencia do genótipo sobre a produção e composição do leite de cabra, mostraram que a raça impacta significativamente a produção de leite, sendo a Saanen a de maior produção leiteira na região. Em contrapartida, LEUTHIER et al. (2004), ao estudarem a influência da raça e do turno de ordenha nos teores de proteínas do leite de cabras, observaram que a raça Anglo-nubiana apresentou a maior concentração de proteína, média de 3,55\% e a Parda Alemã a menos, média de 3,01\%.

Quanto à ordem de parto, GraminHA et al. (1999) relataram maiores produções nas cabras de terceira lactação, decrescendo progressivamente até a sétima lactação. Enquanto CARNICELLA et al. (2008) descreveram maiores rendimentos do leite de cabras de terceira e quarta ordem de parto.

A composição química do leite varia ao longo do período de lactação. Gomes et al. (2004) observaram que os teores de sólidos totais, gordura e lactose diminuíram com o avançar da lactação, porém, os teores de proteína permaneceram praticamente estáveis.

Diante do exposto, objetivou-se avaliar a produção média diária, as variações nos constituintes físico-químicos e agentes microbiológicos do leite das cabras participantes dos Torneios Leiteiros do Circuito Estadual de Exposições Agropecuárias do Estado do Rio Grande do Norte.

\section{MATERIAL E MÉTODOS}

Foram obtidos dados do controle leiteiro oficial em coletas realizadas durante o Circuito Estadual de Exposições Agropecuárias do Estado do Rio Grande do Norte, no período de abril a outubro de 2009, por meio de amostras de leite de cabras participantes dos torneios leiteiros oficiais da Associação Norteriograndense de Criadores de Ovinos e Caprinos (ANCOC). As amostras forma coletadas em sete municípios diferentes.

Foi montado um banco de dados a partir de informações referentes à lactação de 39 cabras Saanen, seis (6) Toggenburg e 61 mestiças, totalizando 106 animais e obteve-se 111 amostras. As matrizes foram agrupadas em categorias, pela ordem de parto, em primípara e plurípara; estágio da lactação, inicial, de zero dia a 30 dias; pico, de 31 dias a 45 dias e pós-pico, mais de 45 dias; pela idade, estabelecida de acordo com a dentição e seguindo o regulamento do Torneio Leiteiro da ANCOC, novilha ou cabra jovem, animais de até dois dentes definitivos, idade entre $12 \mathrm{e} 15$ meses, cabra jovem, animais com quatro a seis dentes definitivos, idade entre 18 a 24 meses e, cabra adulta, animais com oito dentes definitivos, idade superior a 24 meses.

As ordenhas foram feitas manualmente, as 7 horas e 19 horas. Após a ordenha e pesagem, o leite foi amostrado e armazenado em coletores de 200 $\mathrm{mL}$, devidamente identificados e mantido sob refrigeração entre $4^{\circ} \mathrm{C}$ e $6^{\circ} \mathrm{C}$. No momento da segunda ordenha procedeu-se novamente coleta do leite, completando a capacidade dos coletores, misturado e homogeneizado, tornando-se uma amostra única por animal. Posteriormente, o leite foi congelado até a realização das análises laboratoriais realizadas no Laboratório de Inspeção de Produtos de Origem Animal (LIPOA) da Universidade Federal Rural do Semiárido (UFERSA).

A avaliação das características físico-químicas do leite foi realizada por meio do analisador de leite ultrassônico (Ekomilk Total ${ }^{\circledR}$ ), os que avaliou os seguintes parâmetros: densidade, temperatura, proteína, lactose, gordura, extrato seco desengordurado e $\mathrm{pH}$. O extrato seco total 
(EST) foi calculado como a soma do extrato seco desengordurado (ESD) e da gordura total. Os valores de densidade a $15^{\circ} \mathrm{C}$ foram obtidos por intermédio dos valores de temperatura e densidade. Cada amostra foi analisada em réplica, tomando-se o valor médio.

Para avaliação dos agentes microbiológicos do leite foram feitas diluições sucessivas. Inicialmente diluiu-se $10 \mathrm{~mL}$ de leite puro em $90 \mathrm{~mL}$ de água peptonada obtendo-se a diluição de $10^{-1}$, e a partir daí foram preparadas as demais diluições $\left(10^{-2}\right.$, $10^{-3}$ e $\left.10^{-4}\right)$.

As análises do leite quanto à presença ou não de coliformes tiveram início com a prova presuntiva, que consiste na incubação do leite e suas diluições em caldo lauril sulfato de sódio a $36^{\circ} \mathrm{C} \pm$ $1^{\circ} \mathrm{C}$, por 48 horas. Os tubos com produção de gás foram inoculados em caldo verde brilhante bile lactose a $2,0 \%$ a $36^{\circ} \mathrm{C} \pm 1^{\circ} \mathrm{C}$, por 48 horas (CARdoso et al., 1985). Os tubos positivos no caldo verde brilhante foram replicados e colocados em tubos com caldo para Escherichia coli a $45^{\circ} \mathrm{C} \pm$ $0,2^{\circ} \mathrm{C}$, por 48 horas. Após a leitura foi verificado o número mais provável de coliformes totais e termotolerantes (BRASIL, 2003).

Foi realizada inoculação em placas de Petri das diluições do leite e do Ágar padrão para contagem (PCA) visando à determinação de micro-organismos mesófilos. Todas as análises foram conduzidas em réplica. As placas foram mantidas em estufa a $36^{\circ}$ C, por 48 horas (BRASIL, 2003).

Os dados foram analisados estatisticamente assumindo o delineamento inteiramente casualizado. As diferenças entre as médias, dentro de categoria, foram avaliadas usando-se o teste de Tukey a $95 \%$ de probabilidade. Os procedimentos estatísticos foram efetuados usando-se o programa Statistical Analysis System (SAS) versão 8/2003.

\section{RESULTADOS E DISCUSSÃO}

As cabras pluríparas apresentaram maiores $(\mathrm{P}<0,05)$ médias de produção de leite no início $(4,409 \mathrm{~kg})$ e no pico $(5,422 \mathrm{~kg})$ de lactação (Tabela 1$)$.

FERNANDÉz (2000) e Rodrigues et al. (2003) também observaram efeito significativo $(\mathrm{P}<0,05)$ da ordem de parto sobre a produção média diária. Isto pode ser explicado, em parte, pela maturidade fisiológica do organismo das fêmeas pluríparas, enquanto as primíparas, por serem jovens, necessitam de um maior e melhor aporte da nutrição para mantença, crescimento e produção.

Cabras pluríparas apresentam maior volume de úbere em relação aquelas de primeira lactação, pois os alvéolos mamários que se desenvolvem em lactações anteriores podem não regredir completamente, mas se adicionam aqueles que são desenvolvidos em lactações subsequentes, aumentando o parênquima secretor (KNIGHT; PEAKER, 1982).

As médias do ponto de congelamento $\left(-0,502^{\circ} \mathrm{C}\right)$, $\mathrm{pH}(6,63)$, densidade $(1,030 \mathrm{~g} / \mathrm{mL})$, gordura $(3,62 \%)$, proteína $(2,94 \%)$, lactose $(4,97 \%)$, extrato seco desengordurado $(8,54 \%)$ e extrato seco total $(11,91 \%)$ não diferiram $(\mathrm{P}>0,05)$ entre as ordens de parto para o mesmo estágio de lactação (Tabela 1).

O ponto de congelamento não diferiu $(\mathrm{P}>0,05)$ entre o leite das cabras primíparas $\left(-0,497^{\circ} \mathrm{C}\right)$ e pluríparas $\left(-0,506^{\circ} \mathrm{C}\right)$. Essa variável é determinada principalmente pelos elementos solúveis do leite, em especial a lactose os minerais (SANTOS; FONSECA, 2007).

Os valores do ponto crioscópico obtidos no presente estudo estão abaixo da faixa $\left(-0,530^{\circ} \mathrm{Ca}-0,564^{\circ}\right.$ C) fixada pela Instrução Normativa $N^{\circ} 37$ (BRASIL, 2000). O congelamento das amostras pode ter favorecido a ocorrência de alterações na composição do leite e, desta forma, contribuído para a diminuição do ponto de congelamento.

Tabela 1 - Valores médios de produção e variáveis físico-químicas de leite de cabras primíparas e pluríparas em diferentes estágios de lactação participantes de torneios leiteiros.

\begin{tabular}{|c|c|c|c|c|c|c|}
\hline \multirow{3}{*}{ Variável } & \multicolumn{6}{|c|}{ Ordem de parto } \\
\hline & \multicolumn{3}{|c|}{ Primípara } & \multicolumn{3}{|c|}{ Plurípara } \\
\hline & Início & Pico & Pós-pico & Início & Pico & Pós-pico \\
\hline PM (kg/dia) & $2,609^{a}$ & $4,194^{\mathrm{a}}$ & $3,915^{\mathrm{a}}$ & $4,409^{b}$ & $5,422^{b}$ & $4,549^{a}$ \\
\hline $\mathrm{PC}\left({ }^{\circ} \mathrm{C}\right)$ & $-0,528^{a}$ & $-0,524^{\mathrm{a}}$ & $-0,440^{\mathrm{a}}$ & $-0,492^{\mathrm{a}}$ & $-0,512^{a}$ & $-0,514^{\mathrm{a}}$ \\
\hline $\mathrm{pH}$ & $6,63^{\mathrm{a}}$ & $6,57^{a}$ & $6,61^{\mathrm{a}}$ & $6,63^{a}$ & $6,65^{\mathrm{a}}$ & $6,67^{a}$ \\
\hline Densidade $\left(\mathrm{g} / \mathrm{cm}^{3}\right)$ & $1,032^{\mathrm{a}}$ & $1,031^{\mathrm{a}}$ & $1,027^{\mathrm{a}}$ & $1,030^{\mathrm{a}}$ & $1,031^{\mathrm{a}}$ & $1,031^{\mathrm{a}}$ \\
\hline Gordura (\%) & $3,82^{\mathrm{a}}$ & $3,89^{\mathrm{a}}$ & $2,84^{\mathrm{a}}$ & $3,72^{\mathrm{a}}$ & $3,65^{\mathrm{a}}$ & $3,78^{\mathrm{a}}$ \\
\hline Proteína (\%) & $3,06^{\mathrm{a}}$ & $3,04^{\mathrm{a}}$ & $2,60^{\mathrm{a}}$ & $2,99^{a}$ & $2,97^{a}$ & $2,98^{a}$ \\
\hline Lactose (\%) & $5,24^{\mathrm{a}}$ & $5,11^{\mathrm{a}}$ & $4,44^{\mathrm{a}}$ & $4,99^{a}$ & $5,00^{\mathrm{a}}$ & $5,02^{\mathrm{a}}$ \\
\hline $\operatorname{ESD}(\%)$ & $8,89^{a}$ & $8,83^{\mathrm{a}}$ & $7,63^{\mathrm{a}}$ & $8,65^{\mathrm{a}}$ & $8,62^{\mathrm{a}}$ & $8,65^{\mathrm{a}}$ \\
\hline EST (\%) & $12,74^{\mathrm{a}}$ & $13,23^{a}$ & $10,20^{\mathrm{a}}$ & $12,37^{a}$ & $12,37^{a}$ & $10,53^{a}$ \\
\hline
\end{tabular}

Médias seguidas de letras iguais na mesma coluna não diferem entre si pelo teste de Tukey ( $>$ > 0,05). PM (produção média); PC (ponto de congelamento); ESD (extrato seco desengordurado); EST (extrato seco total). 
Independente da ordem de parto, não houve diferença $(\mathrm{P}>0,05)$ para o $\mathrm{pH}(6,63)$ do leite. Os valores de $\mathrm{pH}$ são importantes por indicarem a ação negativa dos agentes microbiológicos que podem elevar a acidez do leite através da hidrólise da lactose por enzimas microbianas, formando ácido lático. Dessa forma, acidez elevada pode indicar elevada atividade microbiana, a qual, por sua vez, pode ser dependente da condição de conservação das amostras (PRATA et al.,1998) ou dos procedimentos de higiene, durante o processo de obtenção do leite. Pode ocasionar ainda a coagulação da caseína e, assim, limitar o uso do leite, reduzindo o seu valor comercial do leite.

A densidade do leite não diferiu $(P>0,05)$ entre as diferentes ordens de parto $(1,030 \mathrm{~g} / \mathrm{mL})$. A densidade é o peso específico do leite, cujo resultado depende da concentração de elementos em solução e da porcentagem de gordura. Diversas causas justificam a variação na densidade no leite, entre elas, a temperatura no momento da leitura da densidade, a temperatura do leite e a elevação da gordura e da composição, ou seja, quanto maior o teor de sólidos no leite, maior a densidade (PRASAD et al., 2005).

Densidades mais elevadas $\left(1,037 \mathrm{~g} / \mathrm{cm}^{3}\right)$ foram observadas por ViLAR et al. (2008) no colostro de cabras Saanen. Esses resultados podem ser explicados pela maior concentração dos constituintes em solução, emulsãoesuspensãonocolostroem detrimento aoleite.

Os teores médios de gordura $(3,62 \%)$ não foram influenciados $(P>0,05)$ pelas diferentes ordens de parto. Normalmente, os teores de gordura no leite de ruminantes são profundamente influenciados pela dieta, com os níveis de fibra exercendo papel preponderante. PRASAD; SEngar (2002) relataram níveis mais elevados de gordura $(5,4 \%)$ no leite de cabras de primeira ordem de parto. Médias inferiores foram descritas por ZАмвом et al. (2005), que observaram 3,23\% de gordura no leite de cabras Saanen no início da lactação. Além de fatores metabólicos, variáveis como raça, turno de ordenha, período de lactação, clima, regime de manejo e alimentação são responsáveis pela variação do teor de gordura no leite (Guo et al., 2001; Prasad; SEngar, 2002).

A proteína do leite das cabras não foi afetada ( $\mathrm{P}>$ $0,05)$ pela ordem de parto $(2,95 \%)$. Valores superiores $(3,72 \%)$ foram observados por CostA et al. (2008). Já FERNANDES et al. (2008) encontraram valor médio de $2,70 \%$, sem considerar a ordem de parto e SORYAL et al. (2004) observaram variação de $2,26 \%$ a 3,35\% de proteína no leite de cabras Alpinas.

Teores delactose $(4,97 \%)$, extrato seco desengordurado $(8,54 \%)$ eextrato seco total $(11,91 \%)$ não diferiram $(\mathrm{P}>0,05)$ entre as diferentes ordens de parto. A lactose é o principal carboidrato do leite e tem função de extrema importância, uma vez que controla o volume de leite produzido, atraindo a água do sangue para equilibrar a pressão osmótica na glândula mamária. Os resultados obtidos apresentam-se dentro dos limites estabelecidos pela legislação, em que o valor mínimo para lactose é de 4,30\% (BRASIL, 2004).

Embora não tenha sido observada diferença ( $\mathrm{P}$ > $0,05)$ no teor de extrato seco total do leite durante o início da lactação, considera-se comum esta elevação com a tendência de diminuição no pico da produção e progressivo aumento com o avançar da lactação, quando o volume de leite diminui (ZENG et al., 1997; SORYAL et al., 2004). Resultados similares foram relatados por PRASAD; SENGAR (2002), ao descreverem maiores níveis de extrato seco total (15,8\%) em animais de primeira ordem de parto. Enquanto resultados distintos foram descritos por AGANGA et al. (2002), para os quais os teores de proteína, lipídios e lactose não aumentam ao longo da lactação. Os autores frisam que, particularmente para a proteína, as informações da literatura são controversas quanto ao seu porcentual no transcorrer do período de lactação.

As médias para a produção média, ponto de congelamento, $\mathrm{pH}$, densidade, gordura, proteína, lactose, extrato seco desengordurado e extrato seco total não diferiram $(P>0,05)$ entre as raças avaliadas. Dessa forma, os valores médios serão discutidos considerando todos os genótipos (Tabela 2).

Tabela 2 - Valores médios de produção e variáveis físico-químicas de leite de cabras das raças Saanen, Toggenburg e Mestiças participantes de torneios leiteiros.

\begin{tabular}{|c|c|c|c|c|}
\hline \multirow{2}{*}{ Variável } & \multicolumn{4}{|c|}{ Raça } \\
\hline & Saanen & Toggenburg & Mestiças & Média \\
\hline PM (kg/dia) & $4,424^{a}$ & $4,987^{a}$ & $4,475^{\mathrm{a}}$ & 4,629 \\
\hline $\mathrm{PC}\left({ }^{\circ} \mathrm{C}\right)$ & $-0,503^{a}$ & $-0,454^{a}$ & $-0,508^{a}$ & $-0,488$ \\
\hline $\mathrm{pH}$ & $6,62^{\mathrm{a}}$ & $6,64^{\mathrm{a}}$ & $6,63^{a}$ & 6,63 \\
\hline Densidade $\left(\mathrm{G} / \mathrm{Cm}^{3}\right)$ & $1,030^{\mathrm{a}}$ & $1,028^{\mathrm{a}}$ & $1,030^{\mathrm{a}}$ & 1,030 \\
\hline Gordura (\%) & $3,61^{\mathrm{a}}$ & $3,45^{\mathrm{a}}$ & $3,74^{\mathrm{a}}$ & 3,60 \\
\hline Proteína (\%) & $2,93^{\mathrm{a}}$ & $2,78^{a}$ & $2,99^{a}$ & 2,90 \\
\hline Lactose (\%) & $4,95^{\mathrm{a}}$ & $4,69^{\mathrm{a}}$ & $5,01^{\mathrm{a}}$ & 4,88 \\
\hline ESD (\%) & $8,51^{\mathrm{a}}$ & $8,09^{a}$ & $8,60^{\mathrm{a}}$ & 8,40 \\
\hline EST (\%) & $12,23^{\mathrm{a}}$ & $12,18^{\mathrm{a}}$ & $11,74^{\mathrm{a}}$ & 12,05 \\
\hline
\end{tabular}

Médias seguidas de letras iguais na mesma linha não diferem entre si pelo teste de Tukey $(\mathrm{P}>0,05)$. PM (produção média); PC (ponto de congelamento); ESD (extrato seco desengordurado); EST (extrato seco total). 
PAz et al. (2007) observaram diferenças significativas entre raças na produção, sendo a raça Saanen a de maior produção por lactação. SiLva et al. (2002), avaliando lactações de cabras das raças Toggenburg, Pardo Alpina, Saanen, Alpina Americana e mestiças, também relataram efeitos significativos na produção em função da raça, com melhores resultados para a Toggenburg.

As médias de produção (Tabela 2) são superiores às descritas na literatura (FERREIRA; TRIGUEIRO, 1998; Tholon, 2000; Silvaet al., 2002). Possivelmente, deva-se ao fato da avaliação ter sido feita em animais em condições particulares, isto é, no transcorrer de torneios leiteiros. Os teores referentes aos dados da composição físico-química do leite, a exemplos, gordura $(3,60 \%)$, proteína $(2,90 \%)$, lactose $(4,89 \%)$ e extrato seco total $(12,06 \%)$, foram semelhantes (P > $0,05)$ entre os genótipos.

Entre os componentes do leite, a gordura apresenta maior variabilidade e, de acordo com FolLeY; OTTERBY (1978), varia consideravelmente entre raças e inclusive entre animais da mesma raça. Também RotA et al. (1993) e Voutsinas et al. (1990), avaliando diferentes raças e graus de sangue, encontraram aumento nos teores de gordura com o avançar da lactação.

Analisando os componentes do leite da raça Saanen, CORDEIRO et al. (2003) verificaram valores médios de $3,57 \% ; 2,93 \% ; 4,48 \%$ e $11,82 \%$ para gordura, proteína, lactose extrato seco total, respectivamente. Enquanto QueIrOGA; COSTA (2007), compilando dados de autores que trabalharam com animais da raça Moxotó e mestiços, na região do Nordeste brasileiro, observaram valores médios de proteína variando de $3,22 \%$ a $3,75 \%$, de gordura entre $3,11 \%$ a $4,26 \%$ e extrato seco total entre $12,30 \%$ e $13,21 \%$.

Segundo Morand-FeHr et al. (2007), a variação no teor de proteína deve-se, principalmente, a concentração de nitrogênio não proteico e ao nível de energia da dieta. Sugerindo que os percentuais de caseínas do leite são estabelecidos geneticamente.

PARK et al. (2007), avaliando as características físico-químicas do leite de cabra, descreveram que o pH varia de 6,50 a 6,80. Desta maneira o leite avaliado apresentou valores considerados fisiológicos, com médias para a raça Saanen, Toggenburg e cabras mestiças de 6,63; 6,65 e 6,64, respectivamente.
Não foram observadas diferenças $(P>0,05)$ entre a microbiota do leite, isto é, mesófilos e coliformes fecais para as duas categorias quanto à ordem de parto (Tabela 3) nos diferentes estágios de lactação.

Valores elevados de coliformes fecais (Tabela 3) podem ser explicados pelas condições em que o produto foi obtido. Normalmente, as dependências onde se localizavam as plataformas de ordenha dos torneiros leiteiros têm grande fluxo de visitantes, contribuindo para condições precárias de higiene; principalmente, pelos aerossóis de poeira e fezes formados constantemente pela movimentação em massa. Valores inferiores foram registrados por EGITO et al. (1989) ao registrarem a média de 2,04 log $\mathrm{NMP} / \mathrm{mL}$ de coliformes fecais no leite de cabras. Em outro contexto, mesmo com os equipamentos disponíveis para pré-dipping, nem todos os ordenhadores realizavam o procedimento, explicando, em parte, a elevada contaminação do leite por coliformes fecais. GOTTARID et al. (2008) afirmaram que a microbiótica do leite e seus derivados apresentam uma grande diversificação relacionada com as condições higiênico-sanitárias da ordenha, a conservação do leite, o tipo de processamento, o tempo transcorrido entre a ordenha e o resfriamento, a temperatura de armazenamento e a qualidade microbiológica da água, dentre outros fatores. A legislação brasileira, para o leite de cabra, não estabelece padrões microbiológicos para o leite cru, porém, a contagem média de mesófilos $(5,122$ $\log$ UFC mL), método padrão para a avaliação da qualidade de produtos lácteos, foi inferior à contagem máxima (6 log UFC $\mathrm{mL}$ ) permitida para o leite bovino cru (BRASIL, 2002).

ANDRADE et al. (2008) observaram médias de 3,85 $\log$ UFC mL para mesófilos no leite cru de cabras. Esses valores são inferiores aos obtidos no presente estudo e, possivelmente, devem-se às condições higiênico-sanitárias em que o leite foi obtido. Mesmo em leite caprino UHT, VITTORI et al. (2008) obtiveram contagens de 1,83 log UFC mL de bactérias mesófilas. Enquanto ANDRADE et al. (2008) observaram 1,57 log UFC mL para os mesófilos no leite pasteurizado, indicando que, mesmo após tratamento térmico, ainda há presença de micro-organismos que podem causar infecção alimentar.

Tabela 3 - Valores médios das análises microbiológicas do leite de cabras primíparas e pluríparas em diferentes estágios de lactação participantes de torneios leiteiros.

\begin{tabular}{|c|c|c|c|c|c|c|}
\hline \multirow{3}{*}{ Micro-organismos } & \multicolumn{6}{|c|}{ Ordem de parto } \\
\hline & \multicolumn{3}{|c|}{ Primípara } & \multicolumn{3}{|c|}{ Plurípara } \\
\hline & Início & Pico & Decréscimo & Início & Pico & Decréscimo \\
\hline Coliformes fecais $(\log \mathrm{NMP} / \mathrm{mL})$ & $4,41^{\mathrm{a}}$ & $4,07^{\mathrm{a}}$ & $4,22^{a}$ & $3,33^{a}$ & $3,81^{a}$ & $4,86^{\mathrm{a}}$ \\
\hline Mesófilos (log UFC/mL) & $5,00^{\mathrm{a}}$ & $5,32^{\mathrm{a}}$ & $4,26^{\mathrm{a}}$ & $4,88^{\mathrm{a}}$ & $4,92^{\mathrm{a}}$ & $6,35^{a}$ \\
\hline
\end{tabular}

Médias seguidas de letras iguais na mesma linha não diferem entre si pelo teste de Tukey $(\mathrm{P}>0,05)$. 


\section{CONCLUSÃO}

A ordem de parto influenciou positivamente a produção de leite; o leite das matrizes, primíparas e pluríparas, apresentou características físico-químicas emicrobiológicas similares. Ogenótiponão interferiu na produção, na composição físico-química e nem na microbiota do leite.

\section{REFERÊNCIAS}

AGANGA, A. A.; AMARTEIFIO, J. O.; NKILE, N. Effect of stage of lactation on nutrient composition of Tswana sheep and goat's milk. Journal of Composition and Analysis, v.15, n.5, p.533- 543, 2002.

ANDRADE, P.V.D.; SOUZA, M.R.; PENNA, C.F.A.M.; FERREIRA, J.M. Características microbiológicas e físico-químicas do leite de cabra submetido à pasteurização lenta pós-envase e ao congelamento. Ciência Rural, v.38, n.5, p.1424-1430, 2008

BRASIL, Ministério da Agricultura. Instrução Normativa $n^{\circ} 37$ de 31 de outubro de 2000. Regulamento técnico de produção, identidade e qualidade de leite de cabra.

Diário Oficial da União, Brasília, p.23, 8 nov. 2000. Seção 1

BRASIL, Ministério da Agricultura. Instrução Normativa $n^{\circ} 62$ de 26 de Agosto de 2003. Oficializa os Métodos Analíticos Oficiais para Análises Microbiológicas para Controle de Produtos de Origem Animal e Água. Diário Oficial da União, Brasília, p.14, 18 set. 2003. Seção 1.

BRASIL. Ministério da Agricultura, Pecuária e Abastecimento. Leite: Instrução Normativa n ${ }^{\circ} 51$ de 18 de setembro de 2002. Brasília: MAPA/SE. 2004. 95p

CARDOSO, W.M.; SILVA, G.G.; CANO, V. Contagem de microorganismos. In: CARDOSO, W.M. (Ed.). Análise microbiológica de alimentos. Rio de Janeiro: Merk, 1985. p.20-27.

CARNICELLA, D.; DARIO, M.; AYRES, M.C.C.; LAUDADIO, V.; DARIO, C. The effect of diet, parity, year and number of kids on milk yield and milk composition in Maltese goat. Small Ruminant Research, v.77, p.71-74, 2008.

CORDEIRO, P.R.C.; BORGES, C.H.P.; BRESSLAU, S. Análise dos componentes do leite de cabra de rebanhos da região a Zona da Mata Mineira e Serrana Fluminense. In: CONGRESSO ESTADUAL DE CAPRINOS E OVINOS, 1., 2003, Nova Friburgo. Anais. Nova Friburgo, 2003.

COSTA, R.G.; MESQUITA, I.V.U.; QUEIROGA, R.C.R.E.; MEDEIROS, A.N.; CARVALHO, F.F.R.; BELTRÃO FILHO, E.M. Características químicas e sensoriais do leite de cabras Moxotó alimentadas com silagem de maniçoba. Revista Brasileira de Zootecnia, v.37, n.4, p.694-702, 2008.
EGITO, A.S.; PINHEIRO, R.R.; FIGUEIREDO, E.A.P. Avaliação da pasteurização lenta do leite de cabra no controle de coliformes totais. Sobral: EMBRAPA CNPC, 1989. n.12, $12 \mathrm{p}$.

FERNANDES, M.F.; QUEIROGA, R.C.R.E.; MEDEIROS, A.N.; COSTA, R.G.; BOMFIM, M.A.D.; BRAGA, A.A. Características físico-químicas e perfil lipídico do leite de cabras mestiças Moxotó alimentadas com dietas suplementadas com óleo de semente de algodão ou de girassol. Revista Brasileira de Zootecnia, v.37, n.4, p.703710, 2008.

FERNANDÉZ, G. Parámetros productivos de cabras Pardo Alpina y sus cruzas, bajo un régimen de pastoreo. Montevideo: Produccíon Latina, 2000. 12p. Disponível em: <http://www.exopol.com/seoc/docs/715jpiq7.pdf>. Acesso em: 15 abr. 2009.

FERREIRA, M.C.C.; TRIGUEIRO, I.N.S. Produção de leite de cabras puras no Curimataú paraibano durante a lactação. Ciência e Tecnologia de Alimentos, v.18, p.56-61, 1998.

FOLEY, J.A.; OTTERBY, D.E. Availability, storage, treatment, composition, and feeding value of surplus colostrum: a review. Journal of Dairy Science, v.61, p.1033-1060, 1978.

GOMES, V.; PAIVA, A.M.M.; MADUREIRA, K.M.; ARAÚJO, W.P. Influência do estágio de lactação na composição do leite de cabras. Brazilian Journal of Veterinary Research and Animal Science, v.41, n.5, p.339-342, 2004.

GOTTARDI, C.P.T.; MURICY, R.F.; CARDOSO, M.; SCHMIDT, V. Qualidade higiênica de leite caprino por contagem de coliformes e estafilococos. Ciência Rural, v.38, n.3, p.161-174, 2008.

GRAMINHA, C.V.; RESENDE, K.T.; RIBEIRO, S.D.A. Estudo comparativo entre as curvas de produção real e a curva de produção teórica em cabras leiteiras. In: REUNIÃO ANUAL DA SOCIEDADE BRASILEIRA DE ZOOTECNIA, 36., 1999, Porto Alegre. Anais. Porto Alegre: Sociedade Brasileira de Zootecnia, 1999. p.552554.

GUO, M.R.; DIXON, P.H.; PARK, Y.W.; GILMORE, J.A.; KINDSTEDT, P.S. Seasonal changes in the chemical composition of commingled goat milk. Journal Dairy Science, v.84, p.79-83, 2001. Supplement E.

IBGE - INSTITUTO BRASILEIRO DE GEOGRAFIA E ESTATÍSTICA. Censo agropecuário. 2006. Disponível em: <http:/ / www.ibge.gov.br/home/estatistica/econo$\mathrm{mia} /$ agropecuaria/censoagro/2006/agropecuario.pdf $>$. Acesso em: 4 fev. 2009.

KNIGHT, C.H.; PEAKER, M. Development of the mammary gland. Journal of Reproduction and Fertility, v.65, p.621-626, 1982. 
LEUTHIER, S.M.F.; TRIGUEIRO, I.N.S.; FURTUNATO, D.M.N.; SANTOS, T.C.H. Variação nos teores médios de proteínas do leite de cabras. Revista Higiene Alimentar, v.18, n.124, p. 68-74, 2004.

MORAND-FEHR, P.; FEDELE, V.; DECANDIA, M.; LE FRILEUX, Y. Influence of farming and feeding systems on composition and quality of goat and sheep milk. Small Ruminant Research, v.68, p.20-34, 2007. PARK, Y.W.; JUÁREZ, M.; RAMOS, M.; HAENLEIN, G.F.W. Physico-chemical characteristics of goat and sheep milk. Small Ruminant Research, v.68, p.88-113, 2007.

PAZ, R.G.; TOGO, J.A.; LOPEZ, C. Evaluación de parâmetros de producción de leche en caprinos (Santiago Del Estero, Argentina). Revista Científica de Maracaíbo, v.17, p.161-165, 2007.

PRASAD, H.; SENGAR, O.P.S. Milk yield and composition of Barbari goat breed and its cross with Jamunapari, Beetal and Black Bengal. Small Ruminant Reserch, v.45, n.1, p.79-83, 2002.

PRASAD, H.; TEWARI, H.A.; SENGAR, O.P.S. Milk yield and composition of the beetal breed and their crosses with Jamunapari, Barbari and Black Bengal breeds of goat. Small Ruminant Research, v.58, p.195-199, 2005.

PRATA, L.F. PRATA, L.F.; RIBEIRO, A.C.; REZENDE, K.T.; CARVALHO, M.R.B.; RIBEIRO, S.D.A.; COSTA, R.G. Composição, perfil nitrogenado e características do leite caprino (Saanen). Região Sudeste, Brasil. Ciência e Tecnologia de Alimentos, v.18, n.4, p.428-432, 1998.

QUEIROGA, R.C.R.E.; COSTA, R.G. Qualidade do leite caprino de raças nativas do Nordeste do Brasil. In: PEQUENOS RUMINANTES NA AMÉRICA DO SUL: SITUAÇÃO ATUAL E PERSPECTIVAS, 2007, Recife. Anais. Recife: EDUFRPE, 2007. 178p.

RIBEIRO, E.L.A.; RIBEIRO, H.J.S.S. Uso nutricional e terapêutico do leite de cabra. Semina: Ciências Agrárias, v.22, n.2, p.229-235, 2001.

RODRIGUES, R. L. et al. Agricultura patronal e familiar e a produção de leite no Triângulo Mineiro. In:CONGRESSO BRASILEIRO DE ECONOMIA E SOCIOLOGIA RURAL, 41., 2003, Juiz de Fora (MG). Anais. Juiz de Fora, MG: SOBER, 2003. 1-CD-ROM.

ROTA, A.M.; GONZALO, C.; RODRIGUEZ, P.L.; ROJAS, A.I.; MARTÍN, L.; TOVAR, J.J. Effects of stage of lactation and parity on somatic cell counts in milk of Verata goats and algebraic models of their lactation curves. Small Ruminant Research, v.12, n.2, p.211-219, 1993.

SANTOS, M.V.; FONSECA, L F.L. Estratégia para controle de mastite e melhoria da qualidade do leite. 2.ed. Barueri: Manole, 2007. 314p.
SANZ SAMPELAYO, M.R.; CHILLIARD, Y.; SCHMIDELY, P.; BOZA, J. Inlfuence of type of diet on the fat constituents of goat and sheep milk. Small Ruminant Research, v.68, n.1/2, p.42-63, 2007.

SILVA, F.L.R.; ANDRADE, V.O.; LIMA, F.A.M. Produções parciais e total de leite em cabras mestiças no Ceará. In: SIMPÓSIO NACIONAL DE MELHORAMENTO ANIMAL, 4., 2002, Campo Grande. Anai. Campo Grande: Sociedade Brasileira de Melhoramento Animal, 2002. Disponível em: <http://www.sbmaonline.org.br/anais/ iv/trabalhos/ovinos/ivt01ca.pdf.>.

Acesso em: 5 jun. 2009.

SORYAL, K.A.; ZENG, S.S.; MIN, B.R.; HART, S.P.; BEYENE, F.A. Effect of feeding systems on concentrate of goat milk e yield of Domiati cheese. Small Ruminant Research, v.54, n.1/2, p.121-129, 2004.

THOLON, P. Estudo genético quantitativo de características de importância econômica em caprinos de raça Saanen. 2000. 54f. Monografia (Graduação em Zootecnia) - Faculdade de Ciências Agrárias e Veterinárias, Universidade Estadual Paulista, Jaboticabal, 2000.

VILAR, A.L.T.; COSTA, R.G.; SOUZA, P.M.; MEDEIROS, A.N.; QUEIROGA, R.C.R.E.; FERNANDES, M.F. Efeito da ordem de parição e do período de ordenha na produção e composição do colostro e do leite de transição de cabras Saanen. Revista Brasileira Zootecnia, v.37, n.9, p.1674-1678, 2008.

VITTORI, J.; SCHOCKEN-ITURRINO, R.P.; POIATTI, M.L.; PIGATTO, C.P.; CHIODA, T.P.; RIBEIRO, C.A.M.; GARCIA, G.R.; RAGAZANI, A.V.F. Qualidade microbiológica de leite UHT caprino: pesquisa de bactérias dos gêneros Staphylococcus, Bacillus e Clostridium. Ciência Rural, v.38, n.3, p.761-765, 2008.

VOUTSINAS, L.; PAPPAS, C.; KATSIARI, M. The composition of Alpine goat's Milk during lactation in Greece. Journal of Dairy Science, v. 57, p.41-51, 1990.

ZAMBOM, M.A.; ALCALDE, C.R.; MARTINS, E.N.; SANTOS, G.T.; MACEDO, F.A.F.; HORST, J.A.; VEIGA, D.R. Curva de lactação e qualidade do leite de cabras Saanen recebendo rações com diferentes relações volumoso: concentrado. Revista Brasileira de Zootecnia, v.34, n.6, p.2515-2521, 2005. Suplemento 1.

ZENG, S.S.; ESCOBAR, E.N.; POPHAM, T. Daily variations in somatic cell count, composition and production of Alpine goat milk. Small Ruminant Research, v.26, p.253-260, 1997.

Recebido em $7 / 2 / 11$

Aceito em 4/5/12 